\title{
Paisagem sonora do espaço migrante
}

\author{
RODRIGO PASSOS FELICISSIMO(1)
}

\section{RESUMO}

Este trabalho contextualiza de maneira resumida as pesquisas referentes ao estudo das paisagens sonoras. O texto original deste artigo é procedente do capítulo II - Paisagem Sonora, contextualizado como parte da discussão estabelecida na dissertação apresentada ao Departamento de Geografia da Faculdade de Filosofia, Letras e Ciências Humanas da Universidade de São Paulo. Paisagem Sonora do Espaço Migrante.

Palavras-chave: paisagem sonora, espaço migrante, som, música e geografia.

\section{ABSTRACT}

Soundscape space migrant

This work succinctly contextualizes the research for the study of soundscapes. The original text of this article is coming from Chapter II - Soundscape, contextualized as part of the discussion established in the dissertation submitted to the Department of Geography, Faculty of Philosophy and Humanities at the University of São Paulo. Soundscape of the Migrante Space.

Keywords: soundscape, migrant space, sound, music and geography.

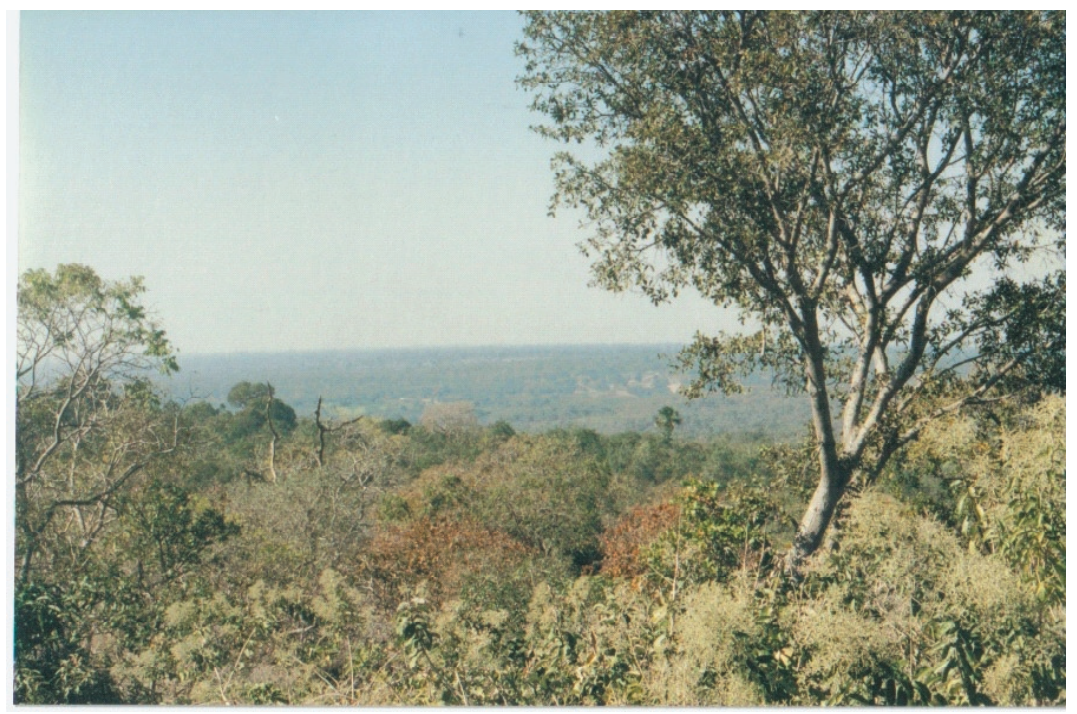

\section{UMA BREVE ABORDAGEM SOBRE O ESTUDO DAS PAISAGENS SONORAS}

As pesquisas desenvolvidas sobre a temática das paisagens sonoras no Brasil são recentes e o que pode ser dito sobre elas, de início, é que tomam por referência os conceitos elaborados pelo pesquisador e músico canadense Murray SCHAFER, que iniciou os estudos das relações entre o homem e os sons do ambiente, questionando a possibilidade da paisagem sonora do mundo ser uma "composição macrocósmica", e nós seus compositores e responsáveis por sua "orquestração". John CAGE (1912-1992), compositor norte americano, seria outra referência importante a ser ressaltada, pois ele amplia os horizontes conceituais da música moderna ao afirmar que a música "são os sons à nossa volta, quer estejamos dentro ou fora das salas de concerto" SCHAFER (1991), ou seja, a música e seu objeto de estudo não se referem tão somente, à análise de partituras, de instrumentos, e de grandes obras da história da música, mas ao estudo do som. O som? Sim o som! O som compreendido como uma nova forma de interpretação 
do conceito musical. Um novo princípio de análise, de um objeto que não propriamente poderia ser identificado como música, anteriormente.

\begin{abstract}
"No inicio da década de 50, CAGE compõe uma obra peculiar chamada de 4'33". Nesta peça de três movimentos que somam o tempo de quatro minutos e trinta e três segundos, o executante deve subir ao palco, se posicionar com seu instrumento e... Não produzir som algum! A primeira e mais famosa apresentação desta obra foi feita pelo pianista David Tudor em 1952, demonstrava "a não existência do silêncio, da permanente presença do som a nossa volta \{...\} 4'33" não é a negação da música, mas a afirmação de sua onipresença". (2)
\end{abstract}

O marco de uma nova proposta instaurada com a composição musical de CAGE 4'33", rompe com a definição clássica da música e atinge a possibilidade de referência para os sons que compõem o ambiente acústico do homem.

$\mathrm{O}$ registro sonoro pode ser contraposto à subjetividade da percepção da escuta dos ouvintes, destacando um grau de sensibilidade variado, de acordo com as características genéticas, físicas individuais e com o grau de treino praticado pelo sistema auditivo. Certo fenômeno sonoro que se apresenta imperceptível para um ouvinte pode, em contrapartida, para outro ouvinte, melhor preparado, caracterizar uma nota, sua freqüência, uma textura e um brilho característico. Quando escutamos uma fonte sonora, é preciso que se tenha conhecimento dos parâmetros de análise com que se pode observar a composição que é característica daquele som, além do valor semântico que ele toma, em uma determinada ocasião. Estes valores podem despertar um momento poético da paisagem, ou uma sensação de desconforto, irritação, dependendo da situação e do grau de exposição à fonte sonora.

"É famosa a experiência realizada pelo compositor que, ao entrar numa câmara anecóica na Universidade de Harvard, totalmente isolada de qualquer som externo, pôde constatar a impossibilidade de um silêncio absoluto, pois continuava a ouvir, ainda, um som agudo (proveniente de seu sistema nervoso) e um som grave (resultado de sua circulação sangüinea)" (IAZZETTA, 1984).

Não se trata aqui de diagnosticar o quanto um determinado ouvinte entrevistado manifesta a sua percepção auditiva, ou o seu grau de apreensão e reflexão dos sons que compõe o seu entorno, seja sobre o domínio da metrópole de São Paulo, ou pela paisagem característica que compõe o universo sertanejo. Mas o que de fato é necessário ressaltar é a mudança drástica que o homem moderno vem sofrendo com o surgimento das máquinas e das tecnologias de ponta, assumindo uma nova realidade sonora no seu cotidiano. O adensamento populacional dos grandes centros globais cria uma nova atmosfera sonora que nos ensurdece cada dia mais. Seja pelos ruídos dos motores de automóveis, das motocicletas, das turbinas de aviões, helicópteros, caminhões, tratores; seja pelos sons eletro-eletrônico de celulares, máquinas registradoras, computadores, impressoras, geladeiras, ar condicionados, lâmpadas florescentes, o que se nota é uma mudança drástica nos patamares sócio-culturais das sociedades modernas. O homem cada vez mais se afasta do que é natural e genuinamente humano, demonstrando estar cada vez mais identificado pelos novos valores do mundo virtual: artificial por essência, criado por ele mesmo.

O "ouvido branco" talvez seja uma expressão interessante para se empregar, um reflexo criado para o atual estágio por que passa o homem social moderno. O branco surge como um manifesto em trazer à luz a não escuta. Pouco se critica, questiona ou comenta sobre o processo de mudança das fontes sonoras produzidas nos ambientes acústicos dos grandes centros urbanos. $\mathrm{O}$ frenesi destes centros compreende o mundo fragmentado que se estabelece diante da escuta banalizada em que o homem moderno se encontra imerso. Não existe um dialogo aberto entre os pares que convivem em sociedade, mas sim um caráter velado e ao mesmo tempo, impositivo de uma forte mídia detentora dos meios de comunicação, aliada aos setores dos meios de produção que estabelecem a dinâmica de todo o sistema produtor de mercadorias, ao qual nos encontramos subjugados. O "ouvido branco" seria a alienação que o ser social encontra para sua própria proteção desta realidade.

\begin{abstract}
"O progresso das civilizações criará mais ruído, e não menos. Disso estamos certos. Com toda a probabilidade, o nível de ruído aumentará não só nos centros urbanos, mas com, o aumento da população e a proliferação de máquinas, o ruído invadirá os poucos refúgios de silêncio restantes no mundo. Daqui a um século, quando o homem quiser fugir para um local silencioso, pode ser que não tenha sobrado nenhum lugar para onde ir". Leo L. BARNEK
\end{abstract}

Pelo texto acima pode-se verificar, através desta aferição pelo pesquisador citado, o questionamento na forma pela qual o homem vem transformando o ambiente acústico no qual ele está integrado, como ser que detém a exclusividade sobre a formação e produção do meio e como ser constituinte do mesmo.

A tabela abaixo, elaborada por Murray SCHAFER, ilustra e evidencia a transformação sonora ocorrida entre os padrões de desenvolvimento das culturas e o aumento dos sons produzidos pelo homem e suas máquinas formidáveis em detrimento ao domínio do meio natural e o uso de seus recursos de forma ilimitada.

${ }^{(2)}$ Fernando IAZZETTA (1984). Neste trecho IAZZETTA faz menção à citação de (NYMAN, 1974). 


\section{PAISAGENS SONORAS MODIFICADAS AO LONGO DA HISTÓRIA}

\begin{tabular}{|l|l|l|l|}
\cline { 2 - 4 } & $\begin{array}{l}\text { Sons } \\
\text { Naturais }\end{array}$ & $\begin{array}{l}\text { Sons } \\
\text { Humanos }\end{array}$ & $\begin{array}{l}\text { Os Sons de Utens ílios e } \\
\text { Tecnologia }\end{array}$ \\
\hline $\begin{array}{l}\text { Culturas } \\
\text { Primitivas }\end{array}$ & $69 \%$ & $26 \%$ & $5 \%$ \\
\hline $\begin{array}{l}\text { Cultura Medieval, } \\
\text { Renascentista e }\end{array}$ & $34 \%$ & $53 \%$ & $14 \%$ \\
\hline $\begin{array}{l}\text { Pré-Industrial } \\
\text { Culturas Pós- }\end{array}$ & $9 \%$ & $25 \%$ & $66 \%$ \\
\hline Industriais & $6 \%$ & $26 \%$ & $68 \%$ \\
\hline
\end{tabular}

SCHAFER (1991)

A tabela nos mostra uma mudança das paisagens sonoras, ao longo de tempos históricos distintos, modificados pelo homem. Verifica-se a perda crescente dos sons naturais em detrimento da expansão do meio antrópico. A partir das três revoluções tecnológicas empreendidas nos últimos 150 anos, o homem ocidental produziu um espaço cada vez mais artificial e ruidoso.

\begin{abstract}
Na cidade a paisagem sonora, a escuta "perderá todo o ponto de referência e todo o conhecimento absoluto de intervalos, comparável ao olho que deve presumir as distâncias em uma superficie idealmente polida". Na "música das ruas" a escuta que a compõe cria um jogo que não restringe ao liso como que fugindo ao estriado, mas que simplesmente flui, passando de um modo a outro, em suas operações de estriagem e de alisamento. Escuta! O trajeto a mobiliza ${ }^{(3)}$.
\end{abstract}

A imagem do satélite Landsat, revela na cor roxa, a produção do espaço metropolitano da grande São Paulo, rodeada pelas áreas verdes da Serra do Mar, da Serra da Cantareira e do Parque Estadual do Jaraguá.

Ao adentrarmos no emaranhado urbano da metrópole, verificamos as tramas sociais que representam o ordenamento espacial de São Paulo. Sabe-se que a formação do ambiente urbano é hierarquizada, segundo a organização dos centros de poder e dos grupos humanos representados. Os extratos sociais são identificados, através do fenômeno do "arraigamento" do homem sobre o solo e da possibilidade deste em se reproduzir no mercado de trabalho.

Um estudo pioneiro a respeito da paisagem sonora de São
Paulo foi realizado pela musicista Regina PORTO (2001). Após obter diversas gravações em localidades estratégicas da metrópole foi elaborada uma composição radiofônica, sobre a diversidade de sons que compõem o substrato urbano da cidade. $\mathrm{O}$ registro da metrópole paulistana foi interpretado e comentado a partir dos parâmetros estéticos pela compositora.

Na cidade de São Paulo, a sujeira sonora é tamanha, e de tal forma explícita e agressiva, que o ouvido se protege por meio de uma auto-anestesia. É uma não escuta. ANHANGABAÚ - Num calmo espaço de menos de cinco minutos, o ouvido cruza pelo menos 20 fontes de músicas ruins, sobrepostas, justapostas, dos mais variados e piores gostos, que competem palmo a palmo pelo mesmo ar e por cada orelha. Como num filme de Lars Von Trier, essa cidade vai ao limite do suportável. Não há espaço sonoro para o espírito. É um não espaço poético. A paisagem sonora é triste e feia. Só há um sentimento possivel por ela: compaixão. Ouvir compassivamente. Para se redimir, a cidade mesma trata de emitir breves "sonzinhos" - preciosos, reluzentes, escondido feito jóia. Que nunca notamos: não ouvimos as estrelas. Um freio de ônibus elétrico, por exemplo, em sua coreográfica, surpreendente, perfeita célula melódica: LA, LA, FA, SI bemol. Quando se notam as pequenas coisas, tudo o que é extraordinário salta ao ouvido. Longe, um homem segue seu triste bordão: barato, barato. São Paulo será isso? Outro bordão se repete por toda a geografia da cidade, o que me leva à conclusão: tudo é real. A cidade é uma sinfonia: real. E talvez custe: um real. Ouvir cansa, dá sono, estressa. Estressa muito. Talvez por concentrar um sentido. $^{(3)}$

\footnotetext{
(3) BUYDENS, Mireille. Sahara, l'esthétique de Giles Deleuze. Paris: J. Vrin, 1990. Op. Citação, p.149. In: mimeografado Fátima Carneiro dos Santos (2004). Universidade Estadual de Londrina, 2004.

${ }^{(4)}$ Mimeografado. Regina PORTO é musicista, jornalista e sound disigner. Dentre os trabalhos que já realizou a respeito das paisagens sonoras está a peça acústica "Metrópoles São Paulo" (2001) e o texto utilizado como referência: "O Bemol da Cidade".
} 
Imagem de satélite da Área Metropolitana de São Paulo

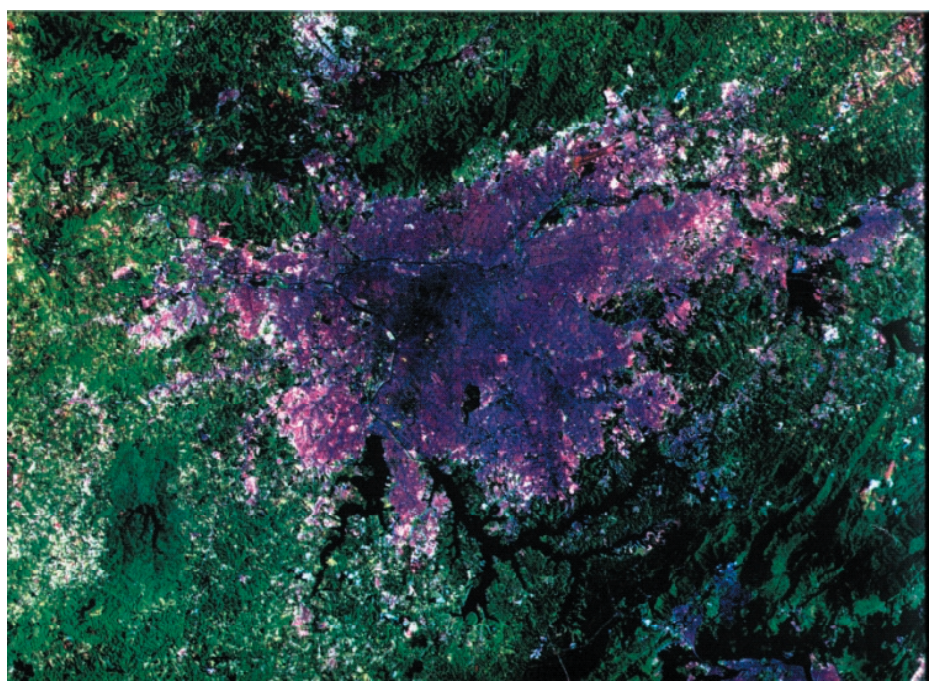

Fonte: Atlas das Unidades de Conservação do Estado de São Paulo, 1998.

“Arranha-Céu" na Metrópole Paulista: Centro Empresarial Complexo Berrini

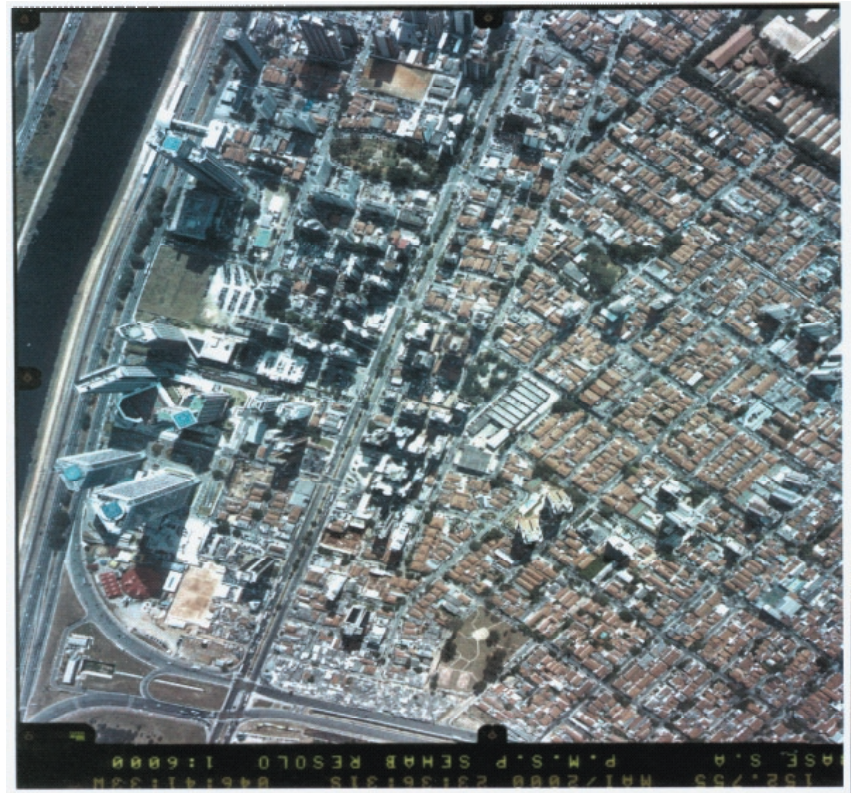

Aerofoto em escala 1: 6.000 .

Data: Março de 2000.

Fonte: Resolo.

A análise do ambiente acústico revela o registro e a reflexão a partir do estudo das fontes sonoras evidenciando os fetiches e os caminhos que a sociedade (pós)-moderna opta, idolatra. Esta escolha repercute no estilo de vida, tanto no centro nevrálgico deste fenômeno (centro urbano da metrópole), quanto nas imediações periféricas que os migrantes ocupam na metrópole e no seu lugar de origem, Morro da Garça (MG). Os padrões tecnológicos e suas influências na paisagem são demonstrados nesta pesquisa, a partir das reflexões realizadas pelos entrevistados, no relato das suas percepções sonoras e parte da sua memória biográfica, no que se refere às questões pertinentes a sua mobilidade e aos sons característicos que revelaram as origens, os destinos individuais entre a vida urbana e seus benefícios e malefícios e a opção de estagnação temporal aos fetiches que o mundo globalizado idealiza, na forma de mercadoria, conhecimento e satisfação individual.

É interessante constatar, por outro lado, que a lógica do capital em sua forma contemporânea global caricatura a expressão do paulistano, no caso, na sua essência. A manifestação da individualidade do paulista se destaca na paisagem urbana contemporânea, sobrepondo-se ao bem estar social da metrópole. O paulistano não questiona o fato de 
conquistar a marca insuportável de 6 milhões de automóveis ${ }^{(5)}$ como trafego total da metrópole. Não existe a menor hipótese em discutir a melhoria em qualidade do transporte público; ao invés disso, congestiona-se diariamente a trama viária da metrópole, em centenas de quilômetros. Não se questiona a indução do mercado privado das grandes montadoras e da mídia no consumo desenfreado de automóveis, ao invés de se priorizar e dinamizar a economia do transporte coletivo. Não se questionam os projetos estruturais de planejamento urbano, ao longo de décadas, que viabilizaram o pacto estabelecido entre o setor publico e o setor privado. Não se questionam as centenas de quilômetros que se formam diariamente ou a percepção do homem urbano, individualista, que prefere se esconder por de trás de seu carro blindado, a enfrentar a realidade caótica que se exprime através da vista que tem do interior de seu carro, com vidro filmado. Não obstante, o mundo globalizado segue esta trilha, que pode ser equiparada a outro fetiche da pósmodernidade: o aparelho celular, pois neste ano completa-se a marca de dois bilhões de aparelhos em uso no mundo, ou seja, $1 / 3$ da população mundial faz uso desta nova tecnologia. Sobre este aspecto imagine-se a paisagem sonora mundial que está por vir. Os sons dos automóveis, celulares e toda a gama de eletro-eletrônicos que rompem as relações tradicionais do homem para transformar a realidade temporal, espacial e sonora no mundo. Enquanto isso, nas áreas periféricas a este sistema, ainda se presenciam os últimos cantos, os chiados do carro de boi, do tear e da máquina de costura manual, da máquina de escrever, do apito a vapor da máquina de 1928 da destilaria do senhor "Fininho", em Morro da Garça (MG). Estes sons encontram-se fadados à extinção e por isto, cabe a esta pesquisa salientar a importância de registrá-los. O que justifica a diferença temporal, técnica diferencial entre o processo de transformação, construção e produção do espaço no sertão mineiro e na metrópole paulistana.

\section{BIBLIOGRAFIA CONSULTADA}

BARNEK, L. L. "Street and Air Traffic Noise - and What Can Be Done About It, "Noise Pollution" in: SANTOS, F. C.

FELICISSIMO, R. P. Paisagem Sonora do Espaço Migrante. São Paulo: USP, 2006. Dissertação - Faculdade de Filosofia, Letras e Ciências Humanas - USP.

IAZZETTA, F. Música: Processo e Dinâmica. Ed. Annablume, 1984.

PORTO, R. “O Bemol da Cidade", Mimeografado. In: Texto Referente à Peça Acústica "Metrópoles São Paulo,” 2001.

SANTOS, F. C. Rethinking Music and the Listening Experience According to Street-Sound Transformation Strategies. In: Mikropolyphonie - The Online Contemporary Music Journal, v. 7, 2001. Endereço: http://farben.latrobe.edu.au - Acessado em 07/01/2004.

SCHAFER, R. M. O Ouvido Pensante. Tradução Marisa Trench Fonterrada, Magda R. Gomes da Silva, Maria Lúcia Pascoal. São Paulo: editora UNESP, 1991. Título Original: The Thinking Ear.

\footnotetext{
${ }^{(5)}$ Segundo o pesquisador José Ouvídio Peres Ramos, do Laboratório de Conforto Ambiental da FAU-USP, ainda não existe um mapa de ruídos dos bairros paulistanos. Em seus estudos, porém o trânsito revela-se como o principal causador de barulho na cidade. "Em relação à década de 80, há mais veículos, mas as ruas são as mesmas", diz. Aviões helicópteros, indústria e comércio, trens e metrôs de superfície são os próximos integrantes da lista. "Sem contar a crescente manutenção da infra-estrutura tecnológica da cidade, geralmente feita à noite. Ao contrário do que se imagina, é à noite que o som do tráfego se intensifica, quando há menos carros na rua". O ruído depende da quantidade de veículos, da velocidade e de quão distantes estão", afirma F. H. Aidar.

Vêm dos veículos os barulhos que mais azucrinam os paulistanos dentro de casa. Segundo dados do Psiu (Programa de Silêncio Urbano da Prefeitura), o ruído médio de veículos lentos é de 84 a 90 decibéis, equivalente ao de uma máquina de cortar grama. Um automóvel a 50km/h, por exemplo, gera uma pressão sonora de 60 decibéis, o que pode ser comparado ao som de uma máquina de costura. Outro, a 100km/h, chega a $75 \mathrm{~dB}$, o som de um restaurante lotado. A marginal está enrugada, então os caminhões trepidam e balançam a carroceria. O IPT (Instituto de Pesquisas Tecnológicas) já mediu 80 decibéis ali, ” diz (consultor Fernando Henrique Aidar). Folha de São Paulo, Domingo, 25 de Setembro de 2005, pagina 1. Matéria de Débora Didonê.
} 